\title{
A presença da criança nos espetáculos da Societas Raffaello Sanzio
}

The presence of children in theatrical productions by
Societas Raffaello Sanzio

Melissa da Silva Ferreira ${ }^{1}$ 


\section{Resumo}

Este artigo aborda os sentidos gerados pela presença de crianças nos espetáculos Genesis, from museum of sleep (1999), Tragedia Endogonidia (2002-2004) e Purgatorio (2008) da companhia teatral italiana Societas Raffaello Sanzio. Desde os anos noventa, a infância tem um papel de destaque no percurso da companhia devido ao modo particular de a criança estar em cena e de ver o mundo e a arte. A criança é vista na cena por Romeo Castellucci como um "messias artaudiano" capaz de perturbar a percepção do espectador da dimensão representacional do espetáculo.

Palavras-chave: Teatro contemporâneo; Infância; Societas Raffaello Sanzio, instabilidade perceptual.

\section{Abstract}

This article discusses the meanings produced by the presence of children in the productions Genesis, from museum of sleep (1999), Tragedia Endogonidia (2002-2004) e Purgatorio (2008), performed by the Italian company Societas Raffaello Sanzio. Since the nineties, infancy has played an important role in the company's productions, due to the specific way children are involved in this process which in turn makes use of the way how they see the world and art. The child is seen on stage by Romeo Castellucci as an "artaudian messiah ", capable of disturbing the spectator's perception of the representational dimension of the theatrical production.

Keywords: Contemporary theatre; childhood; Societas Raffaello Sanzio, perceptual instability. 
O reconhecimento da capacidade das crianças de "entrar no jogo", é a justificativa de Chiara Guidi² para a ampla investigação em torno da infância realizada pela companhia teatral italiana Societas Raffaello Sanzio desde os anos noventa, com a criação de escolas de teatro para crianças e espetáculos infantis. A presença da criança, porém, não fica circunscrita ao mundo infantil, mas marca também os espetáculos do repertório principal da companhia.

A Societas Raffaello Sanzio ganhou destaque no âmbito da arte contemporânea europeia por suas experiências radicais sobre a imagem, a palavra e a presença. $O$ impacto gerado pelas imagens produzidas nos espetáculos, a radicalidade das experiências de linguagem, a presença de animais, máquinas e pessoas com corpos singulares que expõem sua nudez em cenas violentas, inserem a companhia num âmbito que normalmente não vem associado ao universo infantil. Apesar disso, a criança ocupa um lugar central nas práticas e no discurso da Societas Raffaello Sanzio.

A característica comum a todas as obras da companhia em que há a presença da criança é que esta assume um papel fundamental no que diz respeito ao questionamento de valores tácitos ligados ao papel e ao lugar da criança na sociedade. A abordagem de certos tabus faz com que a presença da criança muitas vezes esteja no centro de polêmicas que envolvem o espetáculo como, por exemplo, no caso dos protestos em Paris e Milão, em janeiro de 2012, contra o espetáculo Sul concetto di volto nel figlio di Dio (2010), no qual crianças "atiram granadas" na imagem de Cristo. Ou no segundo ato de Genesi (1999), em que os seis filhos de Romeo Castellucci e Guidi, ainda crianças, atuam sozinhos numa cena denominada "Auschwitz".

Os filhos de Castellucci e Guidi frequentaram intensamente os espetáculos da companhia, de 1999 a 2004: "todos os meus filhos cresceram respirando teatro. Para eles o teatro foi um ambiente antes mesmo que um mundo, antes mesmo que uma linguagem."3 (Castellucci in Abete, 2008, p.1). ${ }^{4}$ Segundo Teodora Castellucci, o teatro fez parte da sua infância de forma natural, "nós nunca tivemos uma explicação: era como comer e beber. Mesmo se era muito cansativo, se eram ritmos muito duros, era

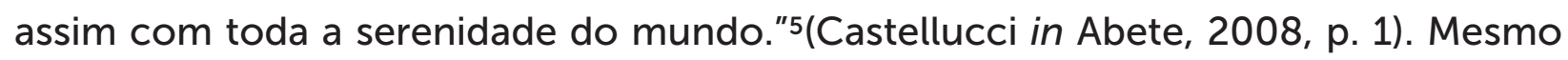
atualmente quando trabalha em sua própria companhia o teatro é para Teodora um jogo, uma brincadeira: "também no meu novo trabalh o, Ken Keen King, eu e Agata sempre falamos que é realmente um jogo."6

Por outro lado, Teodora Castellucci revela que ela e seus irmãos cresceram com receio de que seus professores assistissem aos espetáculos da Socìetas Raffaello Sanzio. Apesar disso, as experiências teatrais vividas na companhia geraram estímulos para carreiras artísticas individuais que não se encerraram na infância. Atualmente, Agata, Teodora e Demetrio trabalham juntos na companhia Dewey Dell. ${ }^{7}$

2 Fundadora da Societas Raffaello Sanzio junto com Romeo Castellucci e Claudia Castellucci, em 1981, em Cesena (Itália).

${ }^{3}[\ldots]$ tutti i miei figli sono cresciuti respirando teatro. Per loro il teatro è stato un ambiente prima ancora che un mondo, prima ancora che un linguaggio.

${ }_{4}^{4}$ Todas as traduções de trechos em língua estrangeiras apresentadas neste artigo são de minha autoria.

5 Non abbiamo mai avuto una spiegazione: era come mangiare e bere. Anche se si faceva molta fatica, se erano ritmi molto duri, era così con tutta la serenità del mondo.

${ }^{6}$ Anche nel mio nuovo lavoro, "Ken Keen King", io e Agata spesso ci diciamo che è veramente un gioco.

7 Além disso, Castellucci manteve, de 2009 à 2012, uma ação performática atuada por ele com seus seis filhos, chamada Storia dell'Africa contemporanea Vol.III, que é baseada na ação de colocar-se de joelhos. 
O surgimento de discussões de cunho ético em torno da participação da criança traz à tona algumas questões fundamentais no que diz respeito aos sentidos gerados pelas presenças infantis na cena. Assim como as outras figuras que marcam os espetáculos de Castellucci, como os corpos singulares de anoréxicos, amputados e laringotomizados, a presença da criança gera no espectador o que Erika Fischer-Lichte denomina de "multi-estabilidade perceptiva", ou seja, produz uma tensão entre o corpo fenomênico do ator e seu personagem. A percepção do espectador entre o corpo do ator, ou seu "ser no mundo", e o personagem atuado por ele, alterna-se continuamente durante o espetáculo, provocando uma desestabilização perceptiva:

[...] o teatro contemporâneo joga com a multi-estabilidade perceptiva. $\mathrm{O}$ foco principal reside no momento de desestabilização, no qual a percepção transita entre o corpo fenomênico e o personagem. O sujeito que percebe fica no limiar entre dois modos de percepção: alternadamente o corpo real do ator e o personagem fictício passam para o primeiro plano. ${ }^{8}$ (Fischer-Lichte, 2008, p. 89).

A multi-estabilidade perceptiva está presente não só nas experiências onde há a participação de atores com características singulares diretamente reconhecíveis, mas caracteriza propriamente o jogo de mão dupla, entre os signos teatrais (no caso aqueles gerados pelo ator) e o olhar do espectador, que configura a teatralidade. Porém, como afirma Fischer-Lichte, em algumas experiências do teatro contemporâneo, esse jogo é conscientemente jogado. Nessas experiências, o foco não estaria na eliminação da dupla percepção, como ocorreu principalmente no teatro do século XIX e início do século XX, mas na desestabilização da percepção, na não fixação, na alternância da percepção entre o corpo fenomênico real e o personagem fictício representado pelo ator.

É interessante perceber como a Societas Raffaello Sanzio lida com a questão dos múltiplos sentidos gerados pela presença da criança na cena nos espetáculos Genesi, from the museum of sleep (1999), Tragedia Endogonidia (2002-2004) e Purgatorio (2008), que serão analisados a seguir.

Em Genesi, from the museum of sleep a criança aparece como protagonista absoluta do segundo ato que trata da "consequência extrema, e não imaginável, da Genesis do homem"9: os campos de concentração de Auschwitz (Castellucci, 2001, p. 264). Auschwitz é apresentado por Castellucci como um espaço totalmente branco, iluminado e silencioso, em que crianças brincam ternamente de Alice no país das maravilhas enquanto recolhem réplicas hiper-realistas de órgãos humanos que descem do teto ou são banhadas por uma ducha de leite que remetem o espectador aos banhos mortais nas câmaras de gás.

Inspirado no primeiro livro da Bíblia Sagrada que narra a criação do mundo da perspectiva cristã, de acordo com Castellucci, Genesi nasce de um desejo de explorar o conceito da criação, ou melhor, a relação entre a criação divina e a recriação, função luciferiana assumida pelo artista: "essa Genesi, assim sendo, é também a minha

\footnotetext{
$8[\ldots]$ contemporary theater plays with perceptive multistability. The main focus lies on the moment of destabilization, in which perception switches between phenomenal body and character. The perceiving subject stands on the threshold between two modes of perception, as
}

alternately the actor's real body and the fictive character step into the foreground.

${ }^{9}[\ldots]$ conseguenza estrema, e non immaginabile, della Genesi dell'uomo. 
pretensão retórica de refazer o mundo, ou seja, em cena, a parte mais vulgar de mim, o artista que quer roubar Deus." 10 (Castellucci apud Chinzari e Ruffini, 2000, p.113). 0 espetáculo se propõe a apresentar postumamente, por isso traz a ideia do museu, o tema mitológico da fundação de três pontos de vista: da criação do mundo, com a figura de Lúcifer e o nascimento de Adão e Eva; da destruição, Auschwitz; e da origem do mal, o fratricídio de Caim.

A dificuldade diante da tarefa de apresentar o irrepresentável no segundo ato de Genesi, de trazer à tona não só a existência, mas a concepção consciente de um espaço de horror, de uma "zona cinzenta"11, criada e posta em prática por seres humanos, por um lado, justifica a escolha de Castellucci da abordagem do tema por contraste. Por outro lado, é interessante perceber a introdução das crianças na cena não só pelo contraste entre o horror da guerra e a pureza angelical, mas pela própria condição do infante, que etimologicamente, significa "aquele que não fala". Em Genesi, as crianças aparecem literalmente como representantes de algo indescritível, que não pode ser transmitido através da fala.

A "zona cinzenta", na origem do termo, refere-se ao processo de degradação moral que ocorreu nos campos de concentração por haver uma inversão sistemática nos papéis de opressor e oprimido. A experiência de estar nessa "zona de irresponsabilidade", conforme Giorgio Agamben (2008), onde não havia distinção entre a exceção e a regra, e sim a naturalização do horror, do inumano, gerava uma impossibilidade de transmissão dessa experiência. Em Genesi, Castellucci evoca através da criança essa impossibilidade de transmissão: "as crianças eram as primeiras a entrar no gás. Não existe uma palavra que chegue até nós de um campo de concentração (a não ser o testemunho de algum sobrevivente, mas feito por um adulto)."12 (2001, p. 264).

No espetáculo13, Eva, Teodora, Cosma, Sebastiano, Demetrio e Agata Castellucci realizam tranquilamente todas as ações que lhes cabem, se mantendo, aparentemente, num alto nível de concentração durante todo o segundo ato. O ritmo lento imposto pela cena dá ao espectador a sensação de estar fora do tempo ou em um novo tempo, que não é o da criança e nem o do adulto, é talvez o tempo da morte, ou do pós-morte.

Ações ocorrem simultaneamente no espaço cênico. Há momentos de imobilidade e outros em que há a realização de uma espécie de partitura corporal, ou coreografia, como no momento da ducha de leite, em que três crianças repetem uma sequência de gestos ligada ao número de letras do seu nome (Castellucci, 2001, p. 244).

A atitude das crianças na cena se alterna entre o contemplar e o agir. As ações, ao mesmo tempo que são precisas, mantêm a espontaneidade infantil como, por exemplo, na cena em que Sebastiano manipula uma xícara e um bule de porcelana vazio e pergunta: "Vocês também querem um chá? Esta é a festa do desaniversá-

\footnotetext{
10 Questa Genesi, cioè, è anche la mia pretesa retorica di rifare il mondo, ovvero in scena, la parte più volgare di me, l'artista che vuole rubare a Dio

${ }_{11}$ A "zona cinzenta", é uma expressão criada por Primo Levi, sobrevivente dos campos de concentração da Segunda Guerra Mundial, e retomada por Giorgio Agamben na elaboração do seu conceito de experiência, para abordar a indescritivel experiência nos campos de concentração: "fomos capazes de
}

compreender e de fazer compreender nossa experiência?" (Levi, 1998). 12 [...] i bambini erano i primi ad entrare nel gas. Non esiste una parola che provenga da noi da un lager (a parte qualche testimonianza di qualche sopravvissuto ma resa da 'adulto').

${ }^{13}$ A descrição desse espetáculo é possível graças ao vídeo de registo do espetáculo disponibilizado pela companhia no Teatro Comandini, em Cesena (Itália), em 2012. 
rio."14(Castellucci, 2001, p. 241). Há nessa cena, por um lado, uma referência evidente ao personagem Chapeleiro Louco de Alice no País das Maravilhas. Por outro lado, as brincadeiras com as miniaturas de porcelana remetem o espectador à sua própria infância, pois mesmo que estas não tenham feito parte de sua vivência pessoal, trazem recordações de filmes infantis e desenhos animados. Por fim, essa cena faz com que o espectador se dê conta que os atores e atrizes são literalmente crianças brincando em cena. Apesar de não serem representadas, as ações contêm a força da repetição própria da criança, que mantém rituais diários formados por gestos, falas e ações.

O caráter de não representação aparece também nos atores que atuam ${ }^{15}$ Caim e Abel no terceiro ato do Genesi. Como aponta Castellucci, "em alguns casos os atores são chamados para ser o que são, invocando a potência da literalidade da forma que repousa em si mesma." 16 (Castellucci in Pirillo, p. 1). A presença objetiva do ator na cena resulta de uma escolha literal feita pelo diretor a partir de uma exigência dramatúrgica. A escolha de um corpo já "pronto", porém, não pretende transformar o espectador em um voyeur, não pretende apresentar a biografia deste corpo, mas nasce de um problema de interpretação anterior ao espetáculo:

Para a escolha do ator que atua em Caim levei em consideração o fato fundamental de que $\mathrm{o}$ ato fratricida precisaria ser, de algum modo, inocente, infantil. Por essa razão procurei por um ator com um braço menor que o outro. $\mathrm{O}$ membro não crescido imediatamente sugere infância, e o jogo que acontece, infelizmente para o próprio Caim, se torna definitivo ou irrevogável17 (Castellucci in Marshall, p. 2).

No caso de Caim, o ator foi escolhido para o papel por ter um braço de criança num corpo de adulto. "Evocar a potência da escolha literal", e optar por uma "presença objetiva" na cena implica que os problemas ligados à interpretação e à representação estejam deslocados no tempo e no espaço. Eles acontecem mais fora da cena, em momentos anteriores e posteriores ao espetáculo, do que na própria cena.

A interpretação que ocorre no momento anterior à cena diz respeito ao processo criativo: o diretor interpreta a obra de referência ou os conteúdos simbólicos ligados à temática do espetáculo e designa corpos específicos para cada papel. Este deslocamento temporal e espacial da interpretação implica uma mudança de atitude do ator na cena, pois já não cabe a ele transformar-se no personagem através de recursos e habilidades técnicas de atuação. $O$ ator é designado para o papel justamente por sua fisicalidade singular para atender às necessidades ligadas à interpretação realizada previamente pelo diretor. $\mathrm{O}$ que é diferente, porém, do modelo do physique du rôle, em que os atores devem se encaixar na descrição dada pelo autor com o objetivo de ser fiel à obra.

\footnotetext{
14 Volete un tè anche voi? Questa è la festa del non compleanno.

15 O termo "atuar o personagem" será utilizado nesse estudo como alternativa aos termos interpretar e/ou representar o personagem. Como o trabalho da companhia Societas Raffaello Sanzio se localiza num território de fronteira entre o teatro e a performance, considerou-se o termo atuar mais adequado para denominar o processo no qual os atores operam na cena como seres ficcionais e suas corporeidades são geradoras de alteridade. O termo é utilizado pelo pesquisador Matteo Bonfitto em suas pesquisas sobre as articulações entre 0 ator e o performer em livros como Cinética do Invisível e Entre 0 ator e 0
}

performer (vide referências bibliográficas).

16 In alcuni casi gli attori sono chiamati per come sono, invocando la potenza della letteralità della forma che riposa in sé stessa.

17 For the choice of the actor that plays Cain I have taken into consideration the fundamental fact that the fratricidal act had to be, in some way, innocent, infantile. For this reason, I searched for an actor with one arm shorter than the other. The un-grown limb immediately suggests childhood, and the game that has, unfortunately for Cain himself, become definitive or irrevocable. 
Por outro lado, os problemas ligados à representação, à interpretação e à atribuição de sentidos deslocam-se também da atuação para a recepção. Diante das imagens apresentadas, o espectador cumpre a tarefa de completar a obra com seu olhar. O espectador é atingido pela presença, pela materialidade dos corpos da cena, o que desestabiliza sua percepção. As tensões produzidas pela dupla percepção dos corpos fenomênicos dos atores e seus personagens, de certa forma, impedem a interpretação imediata daquelas figuras. As "presenças objetivas" na cena (crianças, animais, não atores, máquinas e atores com corpos singulares) não indicam a intenção de apresenta a realidade. Trata-se, portanto, de uma questão de interpretação, que ocorre antes do espetáculo no trabalho do diretor, ou posterior ao espetáculo, no processo de atribuição de sentidos realizado pelo espectador.

Na cena final do segundo ato de Genesi, Castellucci invoca Antonin Artaud para tratar do irrepresentável. $O$ diretor, porém, não procura aplicar os princípios do Teatro da Crueldade na cena. O próprio Artaud é apresentado como uma voz sem corpo, que grita "Je ne suis pas fou! Je ne suis pas fou!"18 Enquanto a voz de Artaud invade todo o espaço do teatro, as crianças em cena correm de um lado para o outro gritando em delírio. Para Castellucci, em Genesi a criança é o messias artaudiano:

O corpo 'finalmente' sem órgãos de Artaud é atuado cientificamente, e num sentido completamente diferente, na câmara de evisceração nazista. A descrição de Artaud da violação do seu corpo nos anos de internamento corresponde àquela do corpo do deportado. E para Artaud a promessa do advir é a mesma da criança. A criança é o messias artaudiano e a criança é a primeira vítima do campo. ${ }^{19}$ (Castellucci, 2001, p. 265).

\section{Como explica a pesquisadora Francesca Manno,}

Messias no sentido de mediador. A palavra messias é a tradução da palavra hebraica mesiah que literalmente significa "ungido". O messias na acepção hebraica e depois cristã (Cristo em grego significa "ungido") é aquele que através da sua mediação produz o advento de um mundo futuro e feliz. Cristo como messias é também a encarnação de Deus. Cristo como vítima inocente que, através da carne e do sangue, tem o poder de transformar o mundo, como o "corpo sem órgãos" de Artaud, como a criança dos campos de concentração, primeiras vítimas sem voz. Então, as crianças são na cena como "corpos puros" no sentido artaudiano. São assim, como o foi Artaud. O corpo delas é atravessado pelo horror inexprimível, do qual se tornam deste modo testemunhas. Mas o corpo delas assim dissecado e torturado se torna "corpo sem órgãos", portador messiânico de uma transformação do mundo, de uma reversão do horror. É a rebelião do filho contra a lei do pai, contra o verbo, o juízo, o sentido de culpa, o destino: rebelião que contém todo o sentido da Crueldade artaudiana e do teatro "pré-trágico", "infantil" dos "Raffaello Sanzio". ${ }^{20}$ (Manno, 2004, p. 138).

\footnotetext{
18 Eu não sou louco! Eu não sou louco!

19 || corpo 'finalmente' senza organi di Artaud è attuato scientificamente, e in tutt'altro senso, nella camera di eviscerazione nazista. La descrizione di Artaud dell'effrazione del suo corpo negli anni di internamento corrisponde a quella del corpo del deportato. E per Artaud la promessa del a venire è quella del bambino. Il bambino è il messia artaudiano e il bambino è la prima vittima del campo. 20 Messia nel senso di mediatore. La parola messia è la traduzione della parola ebraica mesiah che letteralmente significa "unto". II messia nell'accezione ebraica e poi cristiana (Cristo in greco significa "unto") è colui che attraverso la sua mediazione produce l'avvento di un mondo futuro e felice. Cristo come messia è anche l'incarnazione di Dio. Cristo come vittima innocente, che attra-
}

verso la carne ed il sangue ha potere di trasformare il mondo, come il "corpo senza organi" di Artaud, come il bambino dei campi di concentramento, prime vittime senza voce. I bambini, dunque, sono sulla scena come "corpi puri" in senso artaudiano. Lo sono, come lo era stato Artaud. II loro corpo è attraversato dall'orrore inesprimibile, di cui rendono in questo modo testimonianza. Ma il loro corpo così dissezionato e martoriato, diventa il "corpo senza organi", portatore messianico di una trasformazione del mondo, di un capovolgimento dell'orrore. È la ribellione del figlio contro la legge del padre, contro il verbo, il giudizio, il senso di colpa, il destino: ribellione che racchiude tutto il senso della Crudeltà autaudiana e del teatro "pretragico", "infantile" dei "Raffaello Sanzio". 
No programa de sala do espetáculo, Castellucci afirma: "devo mascarar o horror com uma pele de cordeiro."21 O horror de Auschwitz, apesar de não ser literalmente representado, é evocado pela força da própria palavra no imaginário cultural europeu. Em contraste, a presença da criança na cena é conscientemente empregada com o objetivo de gerar uma desestabilização da percepção: "Devo encontrar absolutamente uma dupla corrente, uma dupla sensação, uma dupla emoção para este segundo ato. Tu, o espectador, não deverias saber o que pensar, o que dizer..."22(Castellucci, 2001, p. 265).

A Tragedia Endogonidia não é propriamente um espetáculo, mas um ciclo de onze produções realizadas em dez cidades da Europa durante três anos (2002-2004) pela Societas Raffaello Sanzio. O ciclo se desenvolveu como um sistema aberto de representação que foi se transformando de acordo com a cidade que o hospedava: "A proposta da ideia que estrutura esse conjunto é realmente a de um trabalho em andamento. A Tragedia Endogonidia não é composta por vários espetáculos, mas também não é um único grande espetáculo." (Castellucci in Pitozzi, 2010, p. 134). As produções receberam o nome de episódios e o título de cada um deles foi definido pela primeira letra do nome de cada cidade seguido do número que corresponde à sequência de produções: C.\#01, Cesena; A.\#02, Avignon; B.\#03, Berlin; BR.\#04, Bruxelas; BN.\#05, Bergen; P.\#06, Paris; R.\#07, Roma; S.\#08, Estrasburgo; L.\#09, Londres; M.\#10, Marselha e C.\#11, Cesena. Cada episódio foi apresentado de forma independente e se completava em si mesmo.

A palavra endogonidia é inspirada no vocabulário da microbiologia e referese aos seres hermafroditas que são aptos a se reproduzir infinitamente, "um projeto concreto de imortalidade", sem a presença de um parceiro (Castellucci in Pitozzi, 2010, p. 134). Por seu significado, endogonidia funciona como antítese da tragédia, já que nessa pressupõe-se uma destruição inevitável, a do herói. A palavra endogonidia, portanto, coloca em questão a própria ideia da tragédia.

Em relação à tragédia grega, a principal diferença do ciclo criado por Romeo Castellucci é a ausência do coro. A função do coro na tragédia grega era a de comentar os fatos que eram apresentados nos episódios. Na Tragedia Endogonidia mantêmse apenas os episódios, sem a intervenção do coro, sem comentários, sem uma narrativa. Conforme Romeo Castellucci, a tragédia grega já não pode ser experimentada por dois motivos: o primeiro deles é evidentemente histórico e geográfico. O segundo, é a ausência de uma língua comum e do próprio sentido de comunidade. O coro era a metáfora da sociedade, do povo do lugar onde as pessoas viviam, "e não existe mais o coro. E talvez essa seja a característica da tragédia do futuro."23 (Castellucci in Allen, 2005, p. 1).

A Tragedia Endogonidia não aborda o embate do homem contra o seu destino, mas do homem contra o próprio homem. Os episódios mostram a humanidade em todos os seus matizes, inclusive aqueles que a modernidade tenta esconder com seus

\footnotetext{
21 Devo mascherare l'orrore con una pelle d'agnello.

22 Devo trovare assolutamente una doppia corrente, una doppia sensazione una doppia emozione per questo secondo atto. Tu, o spettatore, non dovresti sapere che cosa pensare, che cosa dire..
} $23[\ldots]$ and there's not a chorus anymore. And maybe this is a characteristic of
the tragedy of the future. 
ideais de bondade. Se, por um lado, as cenas apresentam uma estética e uma temática altamente contemporâneas, por outro, elas remetem a um arcaísmo das relações que, em alguns episódios, se traduzem em uma busca incessante por prazer às custas da dor do outro. Não há, porém, uma moralidade. Não há o bem e o mal, os papéis se invertem continuamente. Há sim, uma abordagem ética profunda, que só pode ser resolvida na individualidade de cada espectador.

A tragédia de Castellucci toca o coletivo por uma via negativa. A justificativa da retomada da tragédia na contemporaneidade relaciona-se com uma visita ao passado, não no sentido do resgate de uma memória, de uma lembrança, mas como uma amnésia. O diretor relaciona-se com a ideia de passado como ruína, como uma ausência, que pode ser sentida, mas já não está presente. Como observa Antonio Audino,

O que busca pôr em evidência a complexa operação da Socìetas é uma raiz ainda mais anterior ao trágico, alguma coisa que mergulha em um passado de tal forma remoto para ser totalmente esquecido no nível intelectual ou consciente, mas que permanece bem presente no nível sensorial. O estado de medo que abrigamos em nós, por exemplo, é um dispositivo animalesco, é um instinto de defesa não regulável através da razão e vontade, reside em zonas cerebrais particulares, "subcorticais" como afirmou muitas vezes o próprio diretor. Assim, aquelas imagens carregadas de inquietude que ele nos apresenta não suscitam angústias pessoais, não movem um estado de fragilidade subjetiva, mas agregam a comunidade de espectadores em um sentido geral e coletivo de apreensão. Se poderia dizer que o trabalho desse encantador evoca e faz manifestar alguns espectros encontrados em uma estação que precede a nossa infância, colocando diante de nós um estado de "terribilidade". ${ }^{24}$ (Audino, 2007, p. 125).

As imagens criadas por Castellucci nos episódios da Tragedia Endogonidia tocam o espectador diretamente num nível sensorial, anterior à palavra, e geram leituras que não são imediatamente racionalizadas e decifradas, resultando numa espécie de enigma. Um enigma que não pode ser resolvido racionalmente, mas apenas intuído. A presença da criança na cena é um dos elementos que têm o poder de deslocar o espectador para esse espaço-tempo não racional, apenas intuído, de sensações provindas de tempos remotos, não se sabe ao certo se da infância, de um sonho ou de um fato esquecido.

Diversos episódios do ciclo apresentam cenas de violência. A participação de crianças nessas cenas, além de gerar uma série de discussões éticas, revelam mecanismos e procedimentos utilizados por Castellucci no processo criativo. As crianças, assim como todas as outras "presenças objetivas" na cena, e a relação que elas estabelecem com os materiais de atuação, funcionam como dispositivos geradores de sensações e percepções no espectador. Os procedimentos e mecanismos que transformam o ator em dispositivo são desmascarados e apresentados ao espectador.

\footnotetext{
24 Quello che cerca di mettere in evidenza la complessa operazione della Socìetas è una radice ancor più anteriore del tragico, qualcosa che affonda in un passato talmente remoto da essere tutto dimenticato a livello intellettuale o conscio, ma che è rimasto ben presente a livello sensoriale. Lo stato di paura che coviamo dentro di noi, ad esempio, è un scatto animalesco, è un istinto di difesa non regolabile attraverso ragione e volontà, risiede in zone cerebrali particolari, "subcorticali" come ha affermato più volte lo
}

stesso regista. Così quelle immagini cariche di inquietudine chi lui ci presenta non suscitano angosce personali, non muovono uno stato di fragilità soggettiva, ma raccolgono la comunità di spettatore in un senso generale e collettivo di apprensione. Si potrebbe dire che il lavoro di questo incantatore evoca e fa manifestare alcuni spettri incontrati in una stagione che precede la nostra infanzia, ponendo davanti a noi uno stato di "terribilità". 
Para Castellucci, as "presenças objetivas" em seus espetáculos devem ser analisadas sempre do ponto vista estético, pois crianças, anoréxicos, velhos e obesos não são colocados em cena para serem exibidos, mas para satisfazer escolhas estéticas que partem da interpretação de um texto ou tema abordado, que os transformam em dispositivos geradores de sentidos. No caso da Tragedia Endogonidia, que foi o primeiro espetáculo da companhia que não partiu de um texto literário ou dramático, a presença de figuras singulares parte de escolhas muito precisas baseadas nas referências visuais e temáticas de cada episódio.

Castellucci costuma usar a palavra figura, e não personagem, para as presenças ficcionais na cena, pois ela implica não só uma ideia, mas uma imagem, que nesse caso está sempre associada ao corpo, "ao ser no mundo" de cada ator, que é escoIhido de acordo com suas características pessoais e sua fisicalidade. A transformação da figura em personagem não ocorre necessariamente no corpo no ator, mas se dá a partir do olhar do espectador.

A transfiguração da figura em personagem, conforme Castellucci, não é uma experiência racional, pois ocorre no corpo do espectador. Cada figura e cada cena carrega uma pluralidade de leituras possíveis que se realizam apenas individualmente em cada espectador. Nas palavras do diretor: "o palco definitivo, o teatro definitivo, está essencialmente na cabeça do espectador, mas eu diria também no corpo do espectador. É uma experiência completamente física." 25 (Castellucci in Chevallier e Mével, 2007, p. 113). É uma experiência física porque é instigada não só pela materialidade dos corpos dos atores, mas também pela ambientação sonora (que é criada pelo músico Scott Gibbons para ser vivida com uma experiência sensorial), pelo cheiro dos animais, e por outros efeitos sensoriais como o vento que sopra no rosto dos espectadores no episódio C.\#11.

A partir da ideia de que a transfiguração ocorre no corpo do espectador, podese afirmar que o foco dos procedimentos criativos de atuação e direção empregados na construção das cenas está na ampliação da percepção sensorial dos espectadores. Essa ideia suscita uma questão: o que é vivenciado em cena pelas crianças e pelos atores e de que forma estas cenas são experienciadas pelo espectador?

Nos episódios B.\#03 e C.\#11 os personagens atuados pelas crianças são assassinados. Esses episódios inserem o espectador dentro de um pesadelo individual e coletivo, afinal, o que pode ser mais terrível e trágico do que o assassinato de uma criança? Em B.\#03, a criança é vítima fatal da própria mãe, já no episódio de Cesena, a criança e sua mãe são vítimas de um jogo de regras impiedoso e impenetrável ligado ao mundo masculino, representado pela máfia. Além dos citados, há a presença de crianças em mais cinco episódios do ciclo: C.\#01, A.\#02, BR.\#04, BN.\#05 e L\#09.

A única cena, porém, em que há efetivamente a representação de um ato de violência contra uma criança na Tragedia Endogonidia é em C.\#11, episódio em que o personagem atuado por Cosma Castellucci recebe um tapa no rosto e é morto a

25 II palcoscenico definitivo, il teatro definitivo, è essenzialmente nella testa dello spettatore, ma io direi anche nel corpo dello spettatore. É un'esperienza completamente física. 
facadas. Em B.\#03, a criança, atuada por Eva Castellucci, aparece em cena já morta, ao lado de sua mãe numa cama de casal. A mãe limpa os vestígios de sangue que estão por todo o quarto, inclusive nos lençóis. A criança é arrastada pelos pés para fora da cena por sua mãe que, em seguida, se masturba com uma boneca. O espetáculo mostra ainda várias mulheres executando gestos e ações obscenos. Em A.\#02, Cosma Castellucci é coberto com uma tinta vermelha, que remete imediatamente a sangue.

É possivel identificar nesses episódios diferentes procedimentos de criação e mecanismos de produção de efeitos estéticos de recepção. No que diz respeito à atuação, não há em nenhum dos episódios do ciclo ações reais de automutilação, não há exposição de biografia pessoal e, por outro lado, não há psicologização na composição de personagens, ou melhor, não há propriamente a composição de um personagem pelos atores. Os atores atuam a partir de ações muito precisas que devem ser cumpridas na cena.

O sangue falso que banha a criança no episódio de Bergen, por exemplo, é um mecanismo que aparece também em outros episódios da tragédia como um código que declara e assume a ficção diante do espectador. Em Bruxelas, um líquido vermelho proveniente de uma garrafa plástica transparente é derramado no chão por dois atores que atuam policiais. Depois disso, um homem é colocado cuidadosamente em cima do líquido e ali ocorre uma cena de espancamento. $O$ líquido vermelho rapidamente se espalha pelo chão e por todo o corpo do ator, transformando-se em sangue diante dos olhos dos espectadores. Se por um lado o líquido vermelho tem um tom provocativo, quase de deboche, por outro lado ele é o anúncio de algo terrível e inevitável. Antes de o homem ser espancado, o sangue já foi derramado. O sangue antecipa a ação. Não há o que fazer para evitar.

Estes procedimentos criativos e mecanismos remetem à fala de Teodora Castellucci em relação ao caráter de brincadeira e de jogo que envolve a participação das crianças nos espetáculos da companhia. Como não há a representação de personagens e os espetáculos não estão centrados na apresentação de uma narrativa linear, as crianças agem numa esfera ficcional que é criada a partir de ações simples e partituras gestuais que são realizadas na cena. Apesar das crianças estarem envolvidas em cenas que produzem imagens chocantes, o choque ocorre no processo de recepção do espetáculo a partir da leitura simbólica do espectador. Na prática, a cena não exige uma preparação psicológica específica para a criação do ser ficcional, como também não ocorre nenhum tipo de mutilação, violência e nem exposição da criança ao risco. O caráter de jogo entre o real e a ficção, assim como no jogo dramático infantil, é conscientemente jogado pelos atuantes da cena, adultos e crianças, e os procedimentos criativos que sustentam o jogo são desmascarados e apresentados ao público, como na já citada cena do sangue falso. Os efeitos gerados por esses procedimentos provocam continuamente a dupla percepção do espectador. Se, por um lado, a criança traz o elemento do real para a cena por ser e estar no palco como ela mesma, por outro, sua presença está sempre a serviço da ficção.

Conforme o ator Sergio Scarlatella26, que atua o homem espancado, os processos criativos dos espetáculos de Castellucci geralmente passam pela descoberta das formas de se relacionar com os materiais de cena (máquinas, objetos, cenogra- 
fia) e pela resolução dos problemas impostos pela execução de ações que já foram definidas previamente pelo núcleo criativo da companhia. $O$ processo de seleção de imagens e referências realizado por Castellucci e Guidi geralmente é mais longo do que o trabalho com os atores. Os ensaios dos episódios da Tragedia, conforme Scarlatella, aconteceram num curto período de tempo, e na maioria das vezes na própria cidade que abrigava o espetáculo.

Com exceção do bebê que é colocado sozinho na cena em BR.\#04, as outras seis crianças presentes na Tragedia Endogonidia são filhos de Castellucci e Guidi. A naturalidade com que Teodora Castellucci descreve a sua participação e de seus irmãos nos espetáculos da Societas Raffaello Sanzio carrega uma semelhança com as dinâmicas de convivência profissional e familiar das companhias medievais, ou do ambiente circense, onde não só a participação, mas a formação das crianças acontece no cotidiano e de forma orgânica, por meio da vivência direta e intensa do teatro e da arte.

Purgatorio, espetáculo que faz parte da trilogia Divina Commedia produzida por Romeo Castellucci para o Festival de Avignon 2008, traz a criança como o centro da ação. Diferente das outras duas partes da trilogia, Purgatorio surpreende a plateia por seu cenário hiper-realista, ambientado numa casa de família burguesa dos anos 70, pensado e construído nos mínimos detalhes.

A primeira cena do espetáculo27, mostra a mãe, atuada por Irena Radmanovic, preparando uma refeição enquanto conversa com seu filho. O menino, atuado por Pier Paolo Zimmermann (com cerca de dez anos), parece solitário e triste. Em diálogo com a mãe, o filho reclama de dor de cabeça. Apesar do diálogo banal, é possível perceber uma certa tensão no ar. Mudanças radicais do cenário revelam ao espectador também o quarto da criança e a sala da casa. Em seu quarto a criança brinca com um robô, vê televisão, se esconde dentro do armário para brincar com uma lanterna. Durante a noite o robô transforma-se num gigante que percorre a casa. A aparição do robô gigante transporta o espectador para o mundo imaginário da criança.

A chegada do pai, atuado por Sergio Scarlatella, de uma viagem de trabalho reforça a sensação anterior de crítica à banalidade da vida cotidiana, com diálogos vazios, gestos e falas repetitivos sobre trabalho. Por outro lado, a banalidade do diálogo vem associada a uma sensação crescente de incômodo, tensão, que gera expectativa no espectador. Os personagens são identificados como a Primeira Estrela (a mãe), a Segunda Estrela (o filho) e a Terceira Estrela (o pai). Legendas projetadas no alto da cena antecipam as ações que serão realizadas: "A Terceira Estrela tirará seu casaco.", "A Terceira Estrela ligará a televisão.", "A Terceira Estrela pedirá à Primeira Estrela se ela pode comer na sala de estar.", "A Primeira Estrela colocará o prato sobre a mesa." As legendas reforçam a sensação de um cotidiano repetitivo e imutável.

Nas cenas seguintes ocorre uma ruptura na aparente normalidade que se apresenta até esse momento. A esposa esquenta o jantar, mas o marido mal toca na comida. Ele parece angustiado. O homem e a mulher se abraçam e ele pergunta: "Onde

26 Ator que trabalha com a companhia desde 2001

${ }^{27}$ A descrição do espetáculo teve como base o vídeo Purgatorio. Produção: La

Compagnie des Indes, Societas Raffaello Sanzio, 2008. DVD, 73 min. 
está o chapéu?". Ela fica confusa e ele diz que a ama. A mulher chora e pede: "Não, por favor, te peço! Esta noite não!", o que num primeiro momento indica uma traição. Ele insiste "Onde está o meu chapéu?" e diante da recusa e do choro dela, o homem vai procurar ele mesmo o chapéu. A mulher continua chorando sozinha na sala. $O$ homem volta com o chapéu nas mãos e pede à mulher que chame o filho, mas ela não se mexe. Ele insiste, e chorando, ela sai da sala. Mãe e filho retornam para a sala. O pai faz perguntas banais para o filho que não parece animado em vê-lo. A mãe sai da sala e deixa os dois sozinhos. O pai mexe com o pé no chapéu que está no chão. Depois lentamente coloca o chapéu na cabeça e olha para o filho. A legenda anuncia: "Agora". O pai pega o filho pela mão e convida: "Vamos brincar com o papai? Vamos para o seu quarto...". A partir desse momento, nota-se uma discrepância entre as legendas e o que ocorre em cena. Além disso, as legendas passam a descrever a cena no presente, e não mais a indicar o que irá acontecer no futuro.

A legenda anuncia: "A Segunda Estrela mostra seus desenhos para a Terceira Estrela. Eles riem juntos. A Primeira Estrela ri também." Mas em cena, o pai diz: "Vamos fazer de conta que somos cowboys, como da última vez...". Na legenda o riso: "ha... ha...ha...". Os dois sobem as escadas enquanto a legenda mostra: "A Primeira Estrela coloca um disco de música ligeira. A Segunda Estrela começa a dançar e a saltar ao redor da sala. A Primeira Estrela e a Terceira Estrela dançam juntas. A Primeira Estrela, a Segunda Estrela e Terceira Estrela estão juntas em casa." Na cena não há desenhos, não há música. Os dois, apenas pai e filho, sobem as escadas lentamente. Antes de entrarem no quarto a legenda anuncia: "Eles escutam a música." A porta se fecha e o espectador fica diante da sala vazia. Somente o silêncio e a legenda "A música." O quarto se localiza fora de cena, num lugar invisível para o espectador, mas é possível ouvir o que se passa lá dentro. A criança começa a chorar e pedir "Não, não, não!" O pai grita "Basta!" e bate no filho. Depois disso, ouve-se a respiração ritmada do pai e os gemidos da criança. O pai continua a gritar: "Basta!" e a criança pede "Não, papai..." e o pai responde: "Abre a boca de novo.". O filho repete chorando "Eu te amo, papai, eu te amo." e o pai insiste: "Abre a boca."

Toda a tensão acumulada pelo espectador até este momento, transforma-se em terror. A cena do estupro parece interminável e é de uma violência extrema, pois ao espectador é dado o mais cruel dos papéis, o de imaginar:

\footnotetext{
Inicia uma violência familiar que "se dilata em um plano de uma inquietude vertiginosa" (Castellucci), revelada pelos gritos do filho que se submete ao físico do pai, pelas palavras dessacralizantes do adulto ("abre mais a boca") e pela inaceitável crueldade de não mostrar a cena, deixando que se plasme na mente do espectador, tornando-o autor e criador daqueles instantes invisíveis. Como no teatro grego, as sequências violentas não são nunca atuadas sobre o palco, são ob-cenas. O espectador ouve somente os sons, os gritos, os impropérios, sendo em tal modo prepotentemente imerso na abstração do terror, na sua forma transparente, na sua essência. ${ }^{28}$ (Ferraresi, 2009, p. 2).
}

\footnotetext{
${ }^{28} \mathrm{Ha}$ inizio una violenza familiare che "si dilata in un piano di una inquietudine vertiginosa" (Castellucci), rivelata dalle urla del bimbo che subisce il fisico del padre, dalle parole dissacranti dell'adulto ("apri di più la bocca") e dall'inaccettabile crudeltà del non mostrare la scena, lasciando che si plasmi nella mente dello spettatore, rendendolo autore
}

e creatore di quegli attimi invisibili. Come nel teatro greco, le sequenze violente non sono mai agite sul palco, sono o-scene. Lo spettatore ne sente solo i suoni, le urla, le imprecazioni, venendo in tal modo prepotentemente immerso nell'astrazione del terrore, nella sua forma vitrea, nella sua essenza. 
Terminada a violência, o pai desce as escadas com uma máscara de borracha hiper-realista que imita o rosto de outra pessoa. Ofegante senta-se ao piano e tira a máscara e o chapéu. Passa a mão pelo rosto angustiado. Olha para as mãos. Com as costas da mão toca as teclas do piano e permanece imóvel. Imediatamente começa a soar uma melodia de piano melancólica, enquanto o filho desce as escadas. Com um fio de sangue que escorre da boca, com a roupa rasgada e ensanguentada, o filho lentamente retira um dos braços do pai do piano, senta em seu colo e o abraça: "Não se preocupe, papai. Acabou. Acabou.".

O conceito do perdão é reelaborado e problematizado. Na doutrina cristã, na qual se inspira o próprio Dante, o purgatório é o lugar onde se espera ganhar o perdão divino através do sofrimento físico. O Purgatorio de Castellucci subverte esta lógica do perdão divino, pois é o pai que necessita do perdão do filho. Porém, a necessidade de consolo, de certa forma, aos olhos do espectador, torna o ato do pai ainda mais imperdoável:

O pai que trai é o Criador que comete um crime contra a criatura. A necessidade de ser perdoado, a necessidade de ser libertado de toda impureza, é aquela do próprio criador. A necessidade humana de abraçar-se é, de fato, a necessidade do Criador na sua abissal solidão. A teologia nos fala, ao contrário da psicanálise, da necessidade de assassinar o filho. ${ }^{29}$ (Castellucci apud Ferrraresi, 2009).

Para Castellucci, a Divina Commedia, desde a sua infância, sempre foi um livro impressionante, um livro de terror:

Sempre me aterrorizou esse aspecto do juízo de Deus, que é inflexível, um juízo de ferro. Diria um Deus que se regozija em ver o suplício dos condenados, condenados por outros, por culpas totalmente humanas. Isso sempre atingiu muito a minha imaginação. [...] É um livro completamente irrepresentável. [...] O que há de mais interessante que o irrepresentável?30 (Castellucci, 2008b).

A cena que só pode ser ouvida, mas não pode ser vista, coloca o espectador numa posição radical: a de ser ele próprio o criador das imagens do horror ao qual é submetido o personagem. As imagens se concretizam somente e individualmente na imaginação de cada espectador. A questão do irrepresentável é mais uma vez trazida à tona por Castellucci, que apresenta o purgatório como o mais próximo ao cotidiano dos três mundos. Devido ao realismo do espetáculo e a presença da criança, a cena do abuso torna-se chocante. Porém, mais chocante ainda é o fato de cada espectador ter que preencher o vazio com suas próprias imagens interiores, provenientes de memórias, sonhos, vivências, pois estas, sim, são reais e aterrorizantes.

Assim como nos espetáculos anteriores, a construção da violência em relação ao que se passa na cena se dá através do olhar do espectador. Scarlatella conta que foi agredido verbalmente por espectadores indignados em praticamente todas as

Il padre che tradisce è il Creatore che commette un crimine contro la creatura. \|l bisogno di essere perdonato, il bisogno di essere liberato da ogni impurità, è quello del Creatore stesso. II bisogno umano di abbracciarsi è, infatti, il bisogno del Creatore nella sua abissale solitudine. La teologia ci dice, a differenza della psicanalisi, la necessità di uccidere il figlio.
Ha sempre me terrorizzato questo aspetto del giudizio di Dio, che è inflessibile, un giudizio di ferro. Se direbbe un Dio che gode in vedere il supplizio dei condannati, condannati per altre per delle colpe del tutto umane. Questo ha sempre colpito molto la mia immaginazione. [...] Ė un libro completamente irrappresentabile. [...] Cosa c'è di più interessante che il irrappresentabile? 
apresentações do espetáculo (informação verbal) ${ }^{31}$. A cena do estupro impactava os espectadores de forma tão intensa que, de certa forma, os limites entre a realidade e a ficção eram borrados. Conforme Castellucci, após as apresentações, muitos espectadores declararam não suportar não só a cena do estupro, mas a cena em que o filho perdoa o pai (informação verbal) ${ }^{32}$.

A centralidade do espectador neste espetáculo, assim como nos outros dois espetáculos da trilogia, é pensada por Castellucci e realizada em diversos detalhes. Conforme o diretor, estes espetáculos foram pensados como um percurso do eu na direção do tu, do artista da direção do espectador. O eu do artista se dissolve, desaparece, para que possa surgir o tu, o espectador.

Esta ideia aparece em diversas passagens de Inferno, como por exemplo, na primeira cena em o próprio Castellucci entra no palco e se apresenta ao público "Je m'appelle Romeo Castellucci", para em seguida ser atacado por cachorros ferozes, como se sua identidade fosse devorada pelos animais, ou na longa cena dos abraços, em que, mais uma vez, o eu, vai na direção do tu. Em Purgatorio essa ideia aparece na forma com que os personagens foram denominados: Primeira Estrela, Segunda Estrela e Terceira Estrela. O espetáculo foi concebido originalmente em francês, portanto, o emprego da palavra "étoile", se justifica por conter em si mesma o "toi" (tu). Desse modo, os personagens seriam o primeiro tu, o segundo tu e o terceiro tu, reportando-se diretamente ao espectador.

Enquanto, por um lado, houve em praticamente todas as apresentações uma resposta violenta do público em relação ao espetáculo, por outro lado, o processo de criação buscou poupar o menino Pier Paolo do conteúdo pesado veiculado pela peça. As vozes do pai e do filho da cena do abuso, conforme Scarlatella e Castellucci, foram gravadas em momentos diferentes. A voz do filho foi gravada num ambiente de jogo, de brincadeira, sem nenhuma espécie de psicologização. Ao menino, não foi revelado o caráter da violência sofrida pelo personagem criança. Foi-lhe explicado apenas que era uma cena em que o pai brigava com o filho. A voz do personagem pai foi gravada por Scarlatella posteriormente, sem a presença do menino. O que o espectador ouvia no espetáculo é resultado de uma montagem. Pier Paolo permanecia no camarim nesse momento do espetáculo e, portanto, não ouvia a cena de violência durante as apresentações.

A participação da criança, nesse espetáculo, toca duplamente em valores tácitos associados à criança na sociedade. Ao mesmo tempo que aborda criticamente a questão do abuso, expõe a criança-ator diante dos espectadores. A criança não é poupada desse olhar e, atuando ela mesma, assume o papel de vítima de uma violência irrepresentável. Assim como em outros espetáculos da companhia, a criança é inserida num contexto que não é aquele associado ao universo artístico infantil, o que implica uma mudança radical na percepção do espectador. Desafiando as questões éticas associadas a estas experiências, a criança é chamada a viver o ambiente

\footnotetext{
31 Entrevista concedida por Sergio Scarlatella, em Porto Alegre (Brasil), em setembro de 2013

32 Diálogo com Romeo Castellucci após a exibição do vídeo de Purgatorio, no cinema do El Cultural San Martín, como parte da programação do Festival Internacional de Buenos Aires, em outubro de 2013.
} 
teatral em toda sua complexidade. E encara o desafio com a naturalidade de quem costuma diariamente transitar pelos diversos mundos presentes na sua imaginação e nos seus sonhos. Estes nem sempre são solares, divertidos e iluminados. Como bem pode lembrar cada adulto, os sonhos infantis muitas vezes carregam consigo o peso sombrio, misterioso, enigmático e aterrorizante dos medos mais profundos.

\section{Referências}

ABETE, Ana. Una famiglia per il teatro. 2008. Disponível em: <http://ilforumdellemuse.forumfree.it/?t=32118016 > Acesso em: 20 out. 2012.

AGAMBEN, Giorgio. O que resta de Auschwitz. Tradução de Selvino J. Assmann. São Paulo: Boitempo Editorial, 2008.

ALLEN, Christopher. Interview with Castellucci. Montclair State University, 2005. Disponível em: <http://jhlinsley.net/romeo-castellucci> Acesso em: 19 abr. 2011.

AUDINO, Antonio. Trasfigurazione - La Biennalle Teatro diretta da Romeo Castellucci. In: AUDINO, Antonio. Corpi e Visioni. Indizi sul teatro contemporaneo. Roma: Artemide, 2007.

CASTELLUCCI, Claudia; CASTELLUCCI, Romeo; GUIDI, Chiara. L'Epopea della polvere. Il teatro della Societas Raffaello Sanzio 1992-1999. Milão: Ubulibri, 2001.

CASTELLUCCI, Romeo. Interview de Romeo Castellucci par Gustav Hofer. In: Societas Raffaello Sanzio. Inferno, Purgatorio, Paradiso. DVD, 200', cor, 2008(b).

CHEVALLIER, Jean Frédéric; MÉVEL, Matthieu. La curvatura del sguardo. Conversazione con Romeo Castellucci. In: AUDINO, Antonio. Corpi e Visioni. Indizi sul teatro contemporaneo. Roma: Artemide, 2007.

CHINZARE, Stefania; RUFFINI, Paolo. Nuova Scena Italiana. Il teatro dell'ultima generazione. Roma: Castelvecchi, 2000.

FERRARESI, Filippo. Divina Commedia - Purgatorio. In: Close up. Storie delle visione, 2009. Disponível em: < http://www.close-up.it/divina-commedia-purgatorio> Acesso em: 11 out. 2012.

FICHER-LICHTE, Erika. The transformative power of performance. London and New York: Routledge, 2008.

LEVI, Primo. É isto um homem? Rio de Janeiro, Rocco, 1998. 
MANNO, Francesca. Il bambino come messia artodiano nel teatro dei "Raffaello Sanzio". In: Segni e Compressione, ano 18, n. 53, p. 132-141, 2004. Disponível em: < http:// siba-ese.unisalento.it/> Acesso: 15 jan. 2010.

MARSHAL, Jonathan. The Castellucci interview: The angel of art is Lucifer. Disponível em: <http://www.realtime.net/article/52/7027> Acesso em: 07 dez. 2011.

PIRILLO, Antônio. Conversando con Romeo Castellucci. In: Culture Teatrali - Studi, interventi e scritture sullo spettacolo. Disponível em:<http://www.cultureteatrali.org/ focus-on/607-conversando-con-romeo-castellucci.html> Acesso em: 10 mar. 2010.

PITOZZI, Enrico. À beira das imagens: o cérebro como tela de projeção. Tradução de Marta Isaacsson. In: Revista Cena (UFRGS), v. 8, p. 131-152, 2010.

\section{Material audiovisual:}

Inferno, Purgatorio, Paradiso. Societas Raffaello Sanzio, Romeo Castellucci DVD, 200', cor, 2008.

Tragedia Endogonidia. Socìetas Raffaello Sanzio, Romeo Castellucci. DVD, cor, 2007.

Registro audiovisual do espetáculo Genesi, from the museum of sleep

Recebido em: 30/09/2014

Aprovado em: 09/11/2014 